\title{
Rapid Deterioration of the Renal Function Caused by the Coexistence of Intratubular Amyloidosis and Myeloma Cast Nephropathy
}

\author{
Hideki Kato ${ }^{1}$, Yoshihide Fujigaki ${ }^{1}$, Shinichiro Asakawa ${ }^{1}$, Yutaka Yamaguchi ${ }^{2}$, \\ Hiroshi Uozaki ${ }^{2}$, Atsushi Komatsuda ${ }^{3}$, Michio Nagata ${ }^{4}$ and Shunya Uchida ${ }^{1}$
}

\begin{abstract}
Multiple myeloma presents with various kidney injuries, including cast nephropathy, light chain deposition disease, and amyloidosis. Cast nephropathy is the most common form and mostly consists of monoclonal immunoglobulin light chains with Tamm-Horsfall protein. Immunoglobulin light chain (AL) amyloidosis may affect all compartments of the kidney, but it is rare in the tubuli. We herein present a rare case with rapid progression of renal failure caused by the co-occurrence of intratubular amyloidosis and cast nephropathy due to multiple myeloma. Our case suggests unique amyloidogenic light chain cast, which can form amyloid fibrils under specific tubular fluid conditions, and illustrates the complicated light chain pathophysiology.
\end{abstract}

Key words: multiple myeloma, intratubular amyloidosis, myeloma cast nephropathy, free light chains

(Intern Med 54: 3023-3028, 2015)

(DOI: 10.2169/internalmedicine.54.5174)

\section{Introduction}

Multiple myeloma is a disease of plasma cell dyscrasia accompanied by the proliferation of clonal $\mathrm{B}$ cell lineage and presents multiple manifestations including renal insufficiency, hypercalcemia, lytic bone lesions, and anemia. Approximately $50 \%$ of all patients with multiple myeloma present with renal insufficiency (1). The most common pathologic feature is myeloma cast nephropathy (light chain cast). Among patients with multiple myeloma, light chains produced from plasma cells can become amyloidogenic in some patients thereby leading to systemic amyloidosis. Amyloidosis is reported to be present in approximately 30\% of monoclonal gammopathies with multiple myeloma and renal involvement (2). Amyloidosis is a systemic disease and is likely to damage all compartments of the kidney, but is rare in the tubuli (3). Therefore, in patients with multiple myeloma, several types of casts can be observed, including light chain casts, Tamm-Horsfall protein casts, hyaline casts, and light chain crystal casts, however, there have been only a few reports of light chain amyloid casts (4).

We herein report an unusual case with a rapid deterioration of the renal function due to multiple myeloma whose renal biopsy revealed the coexistence of intratubular amyloidosis and myeloma cast nephropathy. This case suggests that the intratubular environment may stimulate amyloid formation in situ.

\section{Case Report}

A 74-year-old man visited a local hospital complaining of nausea and vomiting. He had no history of past illness. He never had a health checkup and had not seen any medical doctors after adolescence. He did not take any supplements or drugs. His serum creatinine level was found to be 2.7 $\mathrm{mg} / \mathrm{dL}$ and he was referred to our hospital for further examination of renal insufficiency. His physical examination was unremarkable. The laboratory test showed a BUN concentration of $38.6 \mathrm{mg} / \mathrm{dL}$ and serum creatinine level of 3.5

\footnotetext{
${ }^{1}$ Department of Internal Medicine, Teikyo University School of Medicine, Japan, ${ }^{2}$ Department of Pathology, Teikyo University School of Medicine, Japan, ${ }^{3}$ Department of Hematology, Nephrology, and Rheumatology, Akita University Graduate School of Medicine, Japan and ${ }^{4}$ Department of Kidney and Vascular Pathology, Faculty of Medicine, University of Tsukuba, Japan

Received for publication February 17, 2015; Accepted for publication March 26, 2015

Correspondence to Dr. Yoshihide Fujigaki, fujigaki@med.teikyo-u.ac.jp
} 
$\mathrm{mg} / \mathrm{dL}$. A urine examination was $2+$ protein without occult blood. He had no signs or symptoms of renal failure (Table). Since his baseline serum creatinine level was unknown, his laboratory data were followed up seven days later. The serum creatinine level at this time was $10.0 \mathrm{mg} / \mathrm{dL}$ and he was admitted to our hospital.

The physical examination on admission showed a body weight of $65 \mathrm{~kg}$, which was unchanged from his basal body weight, blood pressure of $132 / 72 \mathrm{mmHg}$ and pulse rate of $50 /$ min. The laboratory data on admission are shown in Table. The hemoglobin level was $11.2 \mathrm{~g} / \mathrm{dL}$, white blood cells count was $6,600 / \mu \mathrm{L}$ with normal differential leukocyte count, total protein was $7.1 \mathrm{~g} / \mathrm{d}$, and albumin concentration was $3.8 \mathrm{~g} / \mathrm{d}$. The urine examinations were $2+$ protein, \pm occult blood in the dip stick test and $2 \mathrm{~g} / \mathrm{gCr}$ of proteinuria. A renal ultrasound showed normal sized kidneys without hydronephrosis. He did not have any signs or symptoms of overhydration or dehydration, and his urine volume had not decreased. Hemodialysis was initiated on the first day of admission. The serum creatinine level before dialysis was gradually decreased to approximately $5 \mathrm{mg} / \mathrm{dL}$ and stabilized after 6 sessions of hemodialysis. Thereafter, hemodialysis was discontinued and a renal biopsy was performed.

The renal biopsy showed 17 glomeruli, presenting two globally sclerosed glomeruli and 15 glomeruli with minor glomerular abnormalities. Mesangial nodular lesions were absent (Fig. 1A). Moderate levels of tubulointerstitial inflammatory cell infiltration were associated with cast formations exclusively in the distal tubules, tubular atrophy and interstitial fibrosis (Fig. 1A). At least 2 types of cast were observed. One was periodic acid-Schiff (PAS)-negative fractured appearance, with neither spicule formation by silver staining nor direct fast scarlet (DFS) positivity (Fig. 1B-D). The other was a PAS-positive core with PAS-negative collar, which corresponds to spicule formation and DFS positivity (Fig. 1E-G). The DFS was negative for glomeruli and vascular vessels (Fig. 1H) and positive mainly for the rim of the casts (Fig. 1I). Some of the casts revealed DFS positivity in the pattern of a tree ring (Fig. 1J) and less frequently DFS positivity for the whole or the center of the casts (Fig. 1K). Immunofluorescence for IgA was slightly positive in the mesangial areas and moderately in the tubular casts (Fig. 2A), but staining for $\operatorname{IgG}, \operatorname{IgM}, \mathrm{C} 3$, and $\mathrm{C} 1 \mathrm{q}$ were negative (data not shown). In the tubular casts lambda was positive (Fig. 2B) and kappa was negative. Renal biopsy specimens were further examined with antibodies specific for human $\gamma$ HC Fab containing CH1 (clone TM15, American Research Products, Belmont, USA), hinge (clone 4E3, Beckman Coulter, Fullerton, USA), CH2 (clone 8A4, AbD Serotec, Oxford, UK) (clone NL16, AbD Serotec), and CH3 (clone A57H, AbD Serotec) domains (5). The IgG-heavy chain $(\mathrm{CH})$ 1, IgG-CH2 and IgG-CH3 were negative (data not shown). By electron microscopy, amyloid fibrils characterized by randomly disposed, nonbranching fibrils with a diameter of approximately $8 \mathrm{~nm}$ were found densely at the periphery and less densely toward the central part of the cast
Table. Laboratory Data on Admission.

\begin{tabular}{|c|c|c|}
\hline \multicolumn{3}{|l|}{ Urinalysis } \\
\hline Gravity & \multicolumn{2}{|l|}{1.013} \\
\hline $\mathrm{pH}$ & \multicolumn{2}{|l|}{5.5} \\
\hline Pro & \multicolumn{2}{|l|}{$2+$} \\
\hline Glu & \multicolumn{2}{|l|}{$(-)$} \\
\hline OB & \multicolumn{2}{|l|}{$( \pm)$} \\
\hline \multicolumn{3}{|l|}{ Sediments } \\
\hline $\mathrm{RBC}$ & $1-4$ & /HPF \\
\hline WBC & $30-49$ & /HPF \\
\hline hyaline cast & + & \\
\hline epithelial cast & + & \\
\hline granular cast & + & \\
\hline waxy cast & + & \\
\hline \multicolumn{3}{|l|}{ Urine chemistry } \\
\hline U-Na & 63 & $\mathrm{mEq} / \mathrm{L}$ \\
\hline U-Cre & 91.6 & $\mathrm{mg} / \mathrm{dL}$ \\
\hline U-TP & 176 & $\mathrm{mg} / \mathrm{dL}$ \\
\hline U-NAG & 17.2 & $\mathrm{U} / \mathrm{L}$ \\
\hline $\mathrm{U}-\beta 2 \mathrm{MG}$ & 30,300 & $\mu \mathrm{g} / \mathrm{L}$ \\
\hline $\mathrm{U}-\alpha 1 \mathrm{MG}$ & 61.2 & $\mathrm{mg} / \mathrm{L}$ \\
\hline \multicolumn{3}{|c|}{ Complete blood count } \\
\hline WBC & 6,600 & $/ \mu \mathrm{L}$ \\
\hline $\mathrm{RBC}$ & $351 \times 10^{4}$ & $4 / \mu \mathrm{L}$ \\
\hline $\mathrm{Hb}$ & 11.2 & $\mathrm{~g} / \mathrm{dL}$ \\
\hline Hct & 33.1 & $\%$ \\
\hline Plt & $21.2 \times 10^{4}$ & )$^{4} / \mu \mathrm{L}$ \\
\hline \multicolumn{3}{|c|}{ Blood Chemistry } \\
\hline $\mathrm{TP}$ & 7.1 & $\mathrm{~g} / \mathrm{dL}$ \\
\hline Alb & 3.8 & $\mathrm{~g} / \mathrm{dL}$ \\
\hline AST & 17 & $\mathrm{U} / \mathrm{L}$ \\
\hline ALT & 9 & UL \\
\hline ALP & 251 & $\mathrm{U} / \mathrm{L}$ \\
\hline rGTP & 18 & $\mathrm{U} / \mathrm{L}$ \\
\hline $\mathrm{LDH}$ & 160 & $\mathrm{U} / \mathrm{L}$ \\
\hline BUN & 75.3 & $\mathrm{mg} / \mathrm{dL}$ \\
\hline Cre & 10.1 & $\mathrm{mg} / \mathrm{dL}$ \\
\hline UA & 9.0 & $\mathrm{mg} / \mathrm{dL}$ \\
\hline $\mathrm{Na}$ & 137 & $\mathrm{mEq} / \mathrm{L}$ \\
\hline K & 5.7 & $\mathrm{mEq} / \mathrm{L}$ \\
\hline $\mathrm{CL}$ & 100 & $\mathrm{mEq} / \mathrm{L}$ \\
\hline $\mathrm{Ca}$ & 8.8 & $\mathrm{mg} / \mathrm{dL}$ \\
\hline iP & 5.9 & $\mathrm{mg} / \mathrm{dL}$ \\
\hline T-Chol & 179 & $\mathrm{mg} / \mathrm{dL}$ \\
\hline TG & 123 & $\mathrm{mg} / \mathrm{dL}$ \\
\hline HDL-C & 27 & $\mathrm{mg} / \mathrm{dL}$ \\
\hline $\mathrm{HbAlc}$ & 5.1 & $\%$ \\
\hline Blood glucose & 102 & $\mathrm{mg} / \mathrm{dL}$ \\
\hline \multicolumn{3}{|l|}{ Serology } \\
\hline IgG & 1,150 & $\mathrm{mg} / \mathrm{dL}$ \\
\hline $\operatorname{Ig} \mathrm{A}$ & 191 & $\mathrm{mg} / \mathrm{dL}$ \\
\hline $\operatorname{IgM}$ & 93 & $\mathrm{mg} / \mathrm{dL}$ \\
\hline CH50 & 60 & $\mathrm{U} / \mathrm{mL}$ \\
\hline $\mathrm{C} 3$ & 113 & $\mathrm{mg} / \mathrm{dL}$ \\
\hline $\mathrm{C} 4$ & 29 & $\mathrm{mg} / \mathrm{dL}$ \\
\hline CRP & 1.47 & $\mathrm{mg} / \mathrm{dL}$ \\
\hline ANA & $\times 40$ & speckled \\
\hline p-ANCA & $<10$ & EU \\
\hline c-ANCA & $<10$ & $\mathrm{EU}$ \\
\hline Anti-GBM Ab & $<10$ & $\mathrm{U} / \mathrm{mL}$ \\
\hline HBs Ag & negative & \\
\hline $\mathrm{HCV} \mathrm{Ab}$ & negative & \\
\hline $\mathrm{TP}-\mathrm{Ab}$ & negative & \\
\hline STS & negative & \\
\hline \multicolumn{3}{|c|}{ Arterial blood gas } \\
\hline $\mathrm{pH}$ & 7.347 & \\
\hline $\mathrm{pCO}_{2}$ & 37.8 & $\mathrm{mmHg}$ \\
\hline $\mathrm{pO}_{2}$ & 95.3 & $\mathrm{mmHg}$ \\
\hline $\mathrm{HCO}^{-}$ & 20.3 & $\mathrm{mmol} / \mathrm{L}$ \\
\hline
\end{tabular}




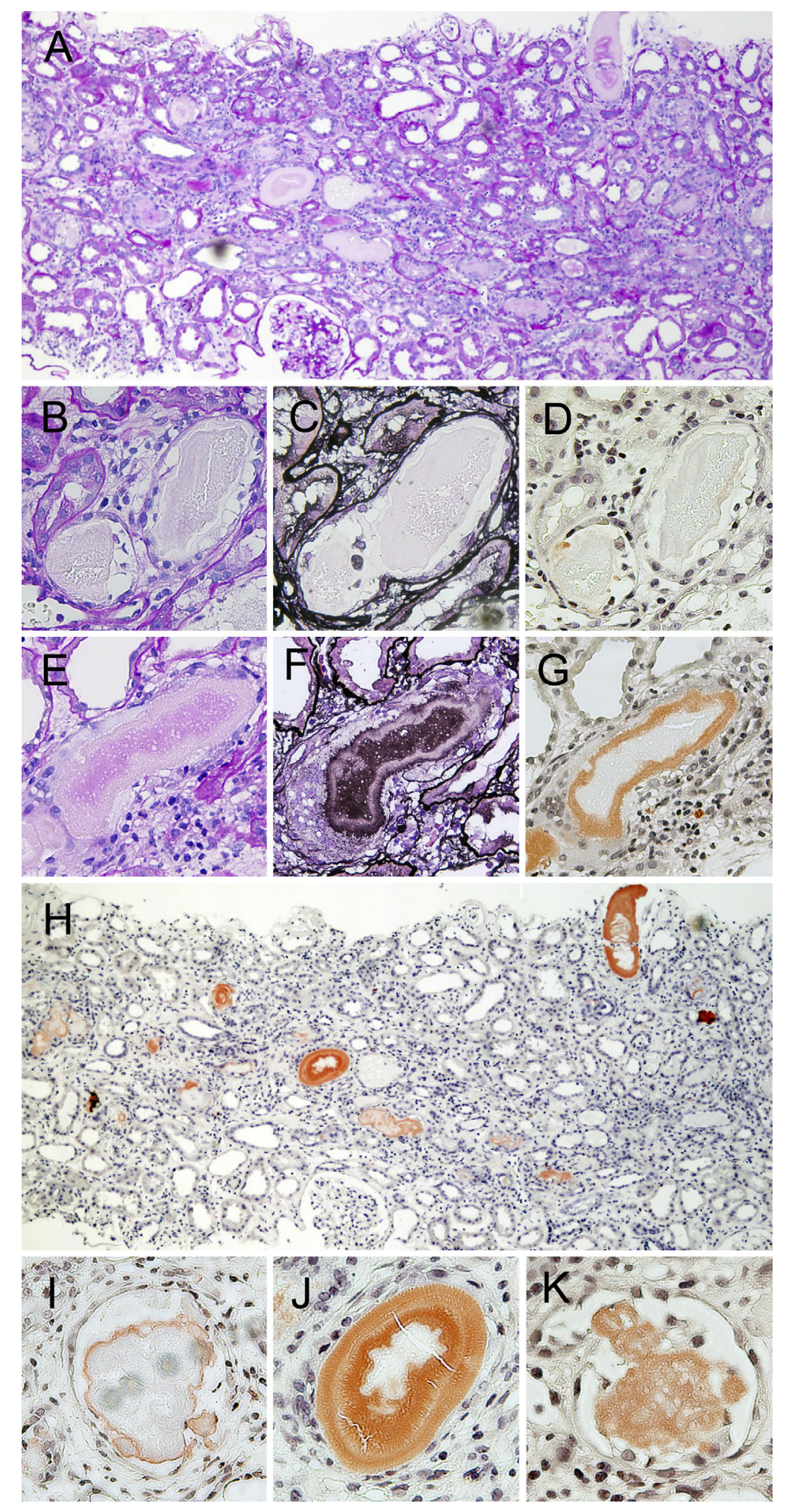

Figure 1. Light microscopic findings. A. PAS shows no major abnormality in the glomeruli, moderate inflammatory cell infiltration, tubular atrophy, interstitial fibrosis, and different types of casts (Original magnification 40x). B-D. PAS (B), periodic acid methenamine silver (PAM)/Hematoxylin and Eosin staining (HE) (C) and DSF staining (D) of consecutive sections of the same cast show PASand DFS-negative casts with no spicule formation (Original magnification 400x). E-G. PAS (E), PAM/ HE (F) and DFS (G) of consecutive sections of the same cast show a PAS-positive core and PAS-negative collar with spicule formation and DFS positivity at the periphery of the cast (Original magnification 400x). H. DFS of the consecutive section of Fig. 1A reveals DFS-positive and -negative casts. Other compartments of the kidney are negative for DFS (Original magnification 40x). I-K. DFS of the casts. DFS is positive at the periphery of the casts in a linear pattern (I), at the double rim of the casts in the pattern of a tree ring $(J)$ and in the whole cast $(K)$ (Original magnification 400x). 

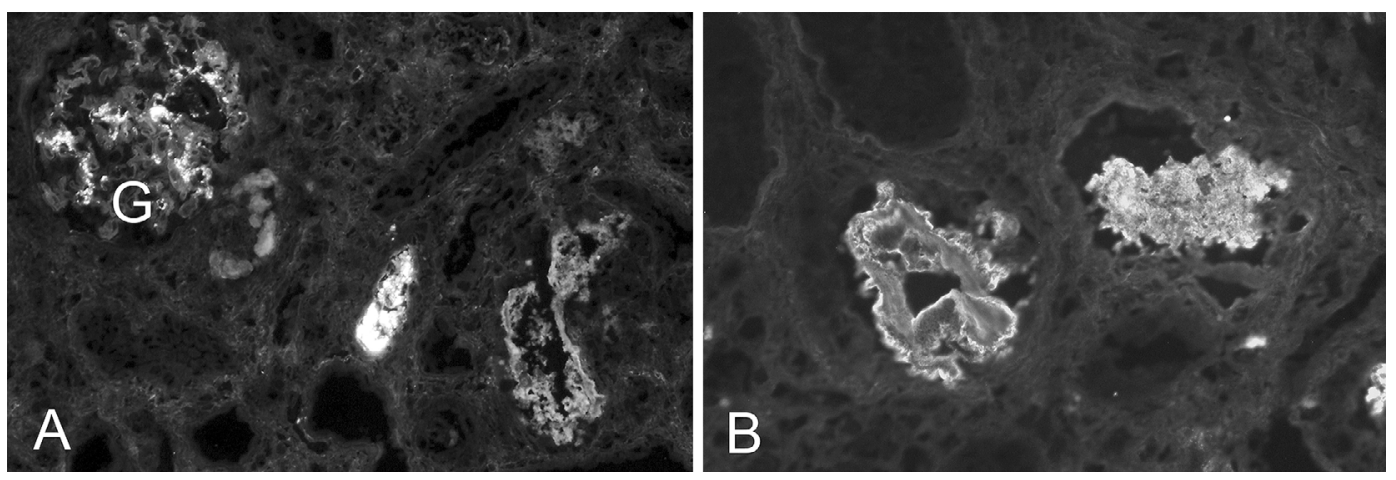

Figure 2. Immunofluorescent findings. A. Immunofluorescence for IgA showing positivity for the glomerulus (G) and intratubular casts (Original magnification 200x). B. Immunofluorescence for lambda shows positivity on the collar of a cast and in the whole cast (Original magnification 400x).

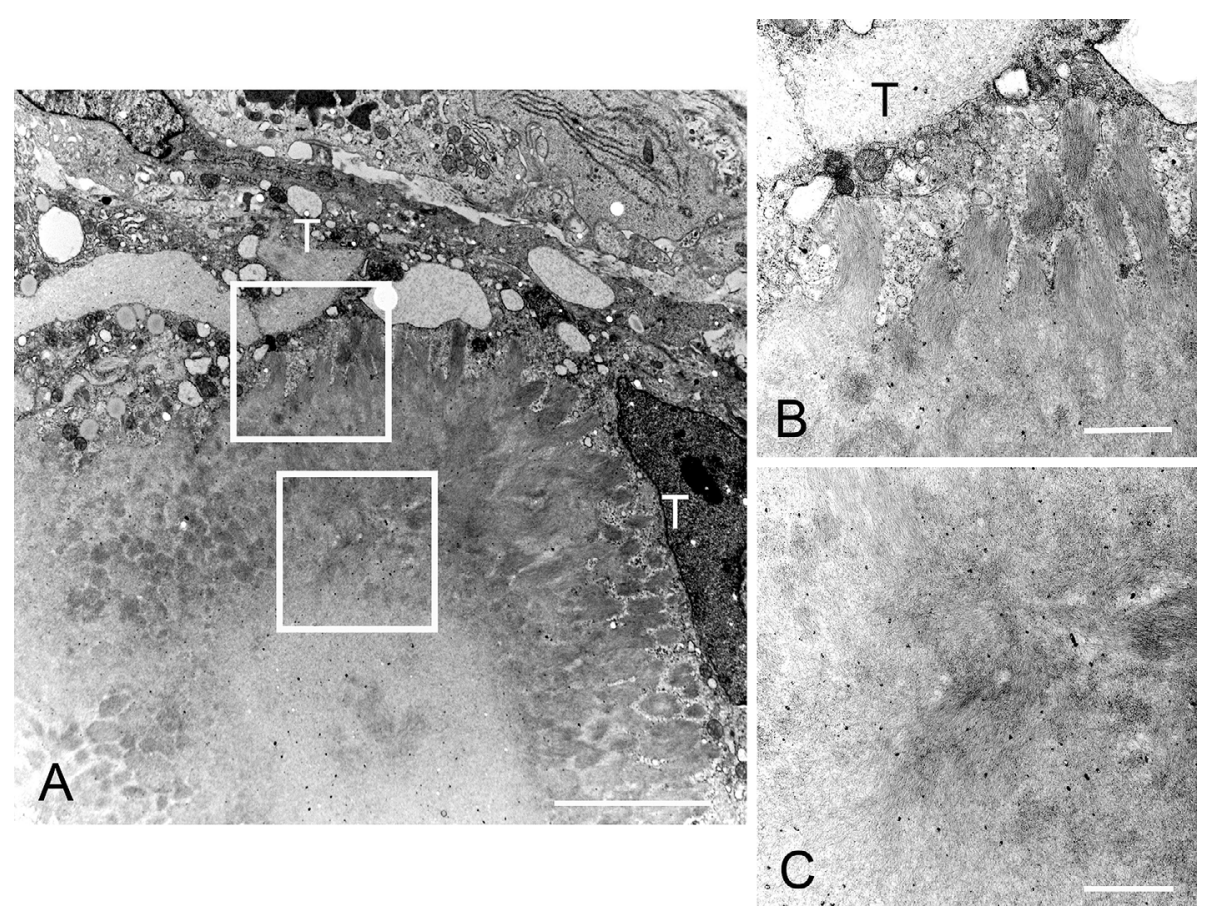

Figure 3. Electron microscopic findings. A. Amyloid fibrils in an intratubular cast. T; degenerative tubular cells. Bar $=5 \mu \mathrm{m}$. B. The area of the upper square in Fig. 3A indicates that amyloid fibrils form a densely parallel organization toward the degenerative tubular cell $(\mathrm{T})$. Bar $=1 \mu \mathrm{m}$. C. The area of the lower square in Fig. 3A shows randomly disposed amyloid fibrils toward the center of the cast. Bar $=1 \mu \mathrm{m}$.

(Fig. 3). The amyloid fibrils, which may correspond to spicule formation, exhibited a densely parallel organization of fibrils rather than an incorporation of the tubular cell components (Fig. 3B). The amyloid fibrils were not found in glomerulus.

Urine immunofixation electrophoresis and serum immunoelectrophoresis identified Bence-Jones IgA lambda type monoclonal proteins. A bone marrow aspiration examination showed cancerous plasma cells and flow cytometry revealed approximately $22 \%$ of CD19(-)56(+)38(+++) plasma cells. Chromosomal abnormality was not observed by G-band staining. The serum kappa and lambda levels were 82.7 and 9,520 mg/L (lambda/kappa ratio: 115), respectively. A bone survey was negative for lytic lesions and pathologic fractures. An echocardiogram showed no ventricular wall thickening and no granular sparkling. According to these findings, we diagnosed the patient with intratubular AL amyloidosis and myeloma cast nephropathy by $\operatorname{IgA}$ lambda light chain type due to multiple myeloma. Chemotherapy with cyclophosphamide, bortezomib and dexamethasone (CyBorD) for induction was initiated six months after the initial admission. Although the patient's serum lambda free light chain (FLC) decreased from the maximal level of 37,000 to 5,040 $\mathrm{mg} / \mathrm{dL}$, the serum creatinine level continued to elevate to $10.2 \mathrm{mg} / \mathrm{dL}$ and permanent hemodialysis was introduced fifteen months after the initial admission. Since the production 
of FLC was relatively suppressed by the chemotherapy and the progression of renal failure was chronic, we introduced standard membrane hemodialysis, not high cut-off membrane hemodialysis, which also has the ability to eliminate FLC $(6,7)$.

\section{Discussion}

There are several characteristic features to distinguish between light chain cast and light chain amyloid cast formation in tubuli. Light chain cast has a fractured appearance, PAS and silver staining negative casts surrounded by inflammatory infiltrates. Light chain amyloid cast has spicule formation at rims, Congo red/DFS-positive, and kappa- or lambda-positive casts (4). The uniqueness of our case is the coexistence of light chain casts and light chain amyloid casts. There have so far been only a few reports of amyloid casts within renal tubular lumens $(4,8-11)$. These reports include casts within renal tubular lumens with and without amyloid glomerular lesions, however, there has been only one previous report showing the coexistence of intratubular amyloid casts and light chain casts without glomerular and vascular amyloid depositions (4), similar to the findings observed in our patient.

Myeloma cast nephropathy is the most common cause of kidney injury in patients with multiple myeloma and often causes acute kidney injury (1). Autopsy studies indicated that approximately 32 to $48 \%$ of multiple myeloma patients had myeloma cast nephropathy (12). Two previous cases with intratubular amyloidosis showed a rapid deterioration of the renal functions, indicating that both amyloid cast and myeloma cast formations can cause a rapid progression of renal failure $(4,8)$. However, it is not known why the deterioration of the renal function was so rapid and why the renal function thereafter partially recovered without any specific treatments in the present patient. At first, we suspected dehydration, however, the patient did not show any signs or symptoms of dehydration. We then speculated that intrarenal hemodynamic alterations, probably due to proximal tubular injury by an overproduction of FLC, obstruction of the tubules by casts and microinflammation on chronic/subacute tubulointerstitial damage, may have contributed to the rapid changes in the renal function observed in this patient.

FLCs are $25 \mathrm{kDa}$ proteins that are filtered through the glomerulus into the tubular ultrafiltrate, and the overproduction of FLC results in the high concentration of FLC in the loop of Henle. Thus casts may form as a result of the binding and subsequent aggregation of monoclonal FLC to Tamm-Horsfall protein (THP), also referred to as uromodulin (12). Furthermore, certain amino acid sequence variations, such as those seen in the CDR3 region of the immunoglobulin FLC, are associated with a high affinity to THP $(3,13)$, and these alterations might have played a role for the myeloma cast nephropathy also observed in our case. It has been assumed that the filtered FLCs form fibrils inside the tubules (3). Structural variations due to genetic mu- tations are suggested to determine the predilection for specific tissue injuries $(4,6)$, since mice injected with FLCs from patients with renal amyloidosis developed similar lesions as those in amyloid patients (14). It would be valuable to know the genetic mutation of FLC in our case. Although numerous factors are associated with the amyloid formation (15), the precise mechanisms of amyloid formation only in the tubular lumen have not yet been determined (8). It is reported that conditions which destabilize FLC folding, such as extreme $\mathrm{pH}$ values and the presence of chemical denaturant urea, promote the aggregation of these proteins as amyloid fibrils in vitro $(16,17)$. These conditions could be achieved in tubular fluid, contributing to intratubular amyloid fibril formation.

The mechanisms to explain the coexistence of the different types of light chain-related diseases, cast nephropathy and intratubular amyloidosis in the same individual like in this case are still unknown. One possibility is that the patient has biclonal plasma cell tumors and each produces different types of FLCs and causes different types of casts. Another possibility is that FLCs with a monoclonal mutation cause non-amyloid cast nephropathy and also serves as precursors to amyloid fibrils. A previous report showed the concurrence of cast nephropathy, arterial amyloidosis and light-chain deposition disease in one individual and only one mutation in the plasma cells was found, suggesting that a monoclonal light chain has a potential to result in diverse phenotypes of light chain-related diseases (13).

In our case, amyloid formation was mainly observed at the rim of the casts and the electron microscopic examination did not indicate the incorporation of tubular cells or tubular droplets. Thus, it may be plausible that amyloidogenic light chain casts transformed into fibril formation from the periphery of the casts or amyloidogenic light chains, which deposited at the periphery of the light chain cast, resulted in fibril formation by exposure to tubular fluid conditions. Furthermore, in some casts, amyloid formation was found at the whole and the center of the casts. These results indicate that unlike light chain casts, unique amyloidogenic light chain can form fibrils directly in the tubular lumen without the incorporation of tubular cells or inflammatory cells.

In summary, we herein presented an unusual case of multiple myeloma with both intratubular amyloidosis and myeloma cast nephropathy. Our case suggests that an amyloid fibril can be formed in tubular fluid independently with extracellular matrices or cellular elements in vivo and illustrates the diversity and complexity of light chain pathophysiology in multiple myeloma.

\section{The authors state that they have no Conflict of Interest (COI).}

\section{Acknowledgement}

We would like to thank Hiromi Yamaguchi for her technical assistance. 


\section{References}

1. Korbet SM, Schwartz MM. Multiple myeloma. J Am Soc Nephrol 17: 2533-2545, 2006.

2. Montseny JJ, Kleinknecht D, Meyrier A, et al. Long-term outcome according to renal histological lesions in 118 patients with monoclonal gammopathies. Nephrol Dial Transplant 13: 1438-1445, 1998.

3. Basnayake K, Stringer SJ, Hutchison CA, Cockwell P. The biology of immunoglobulin free light chains and kidney injury. Kidney Int 79: 1289-1301, 2011.

4. Sethi S, Hanna MH, Fervenza FC. Unusual casts in a case of multiple myeloma. Am J Kidney Dis 54: 970-974, 2009.

5. Komatsuda A, Ohtani H, Sawada K, Joh K, Wakui H. Proliferative glomerulonephritis with discrete deposition of monoclonal immunoglobulin $\gamma 1 \mathrm{CH} 2$ heavy chain and $\kappa$ light chain: a new variant of monoclonal immunoglobulin deposition disease. Pathol Int 63: 63-67, 2013.

6. Hutchison CA, Cockwell P, Reid S, et al. Efficient removal of immunoglobulin free light chains by hemodialysis for multiple myeloma: in vitro and in vivo studies. J Am Soc Nephrol 18: 886895, 2007.

7. Hutchison $\mathrm{CA}$, Heyne N, Airia $\mathrm{P}$, et al. Immunoglobulin free light chain levels and recovery from myeloma kidney on treatment with chemotherapy and high cut-off haemodialysis. Nephrol Dial Transplant 27: 3823-3828, 2012.
8. El-Zoghby Z, Lager D, Gregoire J, Lewin M, Sethi S. Intratubular amyloidosis. Kidney Int 72: 1282-1288, 2007.

9. Vassar PS, Culling CF. Fluorescent amyloid staining of casts in myeloma nephrosis. Arch Pathol 73: 59-63, 1962.

10. Friman $C$, Tornroth $T$, Wegelius $\mathrm{O}$. IgD myeloma associated with multiple extramedullary amyloid-containing tumours and amyloid casts in the renal tubules. Ann Clin Res 2: 161-166, 1970.

11. Melato M, Falconieri G, Pascali E, Pezzoli A. Amyloid casts within renal tubules: a singular finding in myelomatosis. Virchows Arch A Pathol Anat Histol 387: 133-145, 1980.

12. Leung N, Nasr SH. Myeloma-related kidney disease. Adv Chronic Kidney Dis 21: 36-47, 2014.

13. Lorenz EC, Sethi S, Poshusta TL, et al. Renal failure due to combined cast nephropathy, amyloidosis and light-chain deposition disease. Nephrol Dial Transplant 25: 1340-1343, 2010.

14. Solomon A, Weiss DT, Kattine AA. Nephrotoxic potential of Bence Jones proteins. N Engl J Med 324: 1845-1851, 1991.

15. Blancas-Mejia LM, Ramirez-Alvarado M. Systemic amyloidoses. Annu Rev Biochem 82: 745-774, 2013.

16. Kim YS, Cape SP, Chi E, et al. Counteracting effects of renal solutes on amyloid fibril formation by immunoglobulin light chains. J Biol Chem 276: 1626-1633, 2001.

17. Souillac PO, Uversky VN, Millett IS, Khurana R, Doniach S, Fink AL. Effect of association state and conformational stability on the kinetics of immunoglobulin light chain amyloid fibril formation at physiological pH. J Biol Chem 277: 12657-12665, 2002.

(C) 2015 The Japanese Society of Internal Medicine http://www.naika.or.jp/imonline/index.html 